S A Tydskrif vir Bedryfsingenieurswese, vol. 2, No 1, Junie 1988, pp. 1-10

\title{
'n Nuwe Konsep In Vervaardigingstegnologie
}

\author{
P. Brink \\ Lyttelton Ingenieurswerke (Edms) Bpk \\ P.K.Tek \\ Privaatsak $X 5$ \\ Verwoerdburg \\ 0133
}

\section{ABSTRACT}

In-process measuring contributes towards automation in the manufacturing process and can also play an important role in quality by measuring characteristics during production. To enable one to effectively implement and utilize in-process measuring on a specific machine tool, it is essential to develop a system for the calibration and qualification of in-process measuring.

\section{OPSOMMING}

In-prosesmeting dra by tot outomatisasie in vervaardigingsprosesse en kan ook 'n belangrike rol speel vir kwaliteit doeleindes met die meet van karakteristieke tydens produksie. Ten einde in-prosesmeting effektief te implementeer en te benut op 'n spesifieke masjienwerktuig, is die ontwikkeling van ' $n$ kalibrasie- en kwalifikasiestelsel vir in-prosesmeting noodsaaklik. 


\section{INLEIDING}

In moderne metrologie-toepassings tydens masjineringsprosesse is daar hedendags ' $n$ groeiende tendens om die inspeksiefunksie met die masjienwerktuig te kombineer. Die basis van dié filosofie berus daarop dat die masjienwerktuig toegerus word met spesiale meettoerusting en dan tydens produksie ook as ' $n$ meetmasjien gebruik word. Veral met die koms van geoutomatiseerde masjinering, bv. rekenar numeries beheerde (RNB)-masjiene, het die behoefte na 'n outomatiese meetmeganisme, in teenstelling met die konvensionele benadering (waar mikrometer-verniers, klokwysers ens. gebruik word), geweldig gegroei.

In-prosesmeting (IPM) word gedefinieer as ' $n$ metode van meting tydens produksie, war dieselfde masjienwerktuig wat die masjineringsproses uitvoer, ook vir meting gebruik word. 'n Kontaksneller sensor word soos 'n gereedskapstuk in die masjienspil gelaai vir die meetproses. Beheer oor die masjineringsproses kan nou verkry word deur onmiddellike terugvoering van meetresultate. Dit bring die kwaliteitbeheerlus tot by die vervardigingsproses.

In-prosesmeting is 'n relatiewe nuwe begrip in die SuidAfrikanse vervaardigings-industrie. Alhoewel IPM in die buiteland reeds gedurende die sewentigerjare ontstaan het, is daar voortdurend onduidelikhede en vrae m.b.t. kwaliteit en die toepassingsareas van hierdie nuwe meettegnologie. Dit is hoofsaaklik vanwel ' $n$ algemene gebrek aan kennis, ondervinding en die onwilligheid om tyd aan gestruktureerde ondersoeke te bestee.

Die ontwikkeling van 'n kalibrasie- en kwalifikasiestelsel vir in-prosesmeting op ' $n$ RNB-masjien, tesame met kundigheidsvestiging, word as noodsaaklik beskou om sodoende IPM effektief te implementeer en sinvol te gebruik. 


\section{IN-PROSESMETING}

Funksionering:-

Tydens IPM funksioneer die RNB-masjien, tesame met die in-proses meettoerusting (IPMT) analoog aan 'n kobrdinatmeetmasjien. Die verskil is dat inspeksie en beheer nou direk deur die masjienwerktuig gedoen word. Sodra die RNB-masjien ook vir meting gebruik word, word daar verwys na dié masjienwerktuig as ' $n$ in-proses meetstelsel (IPMS). Die sensor gelaai vanaf die gereedskaphouer in die masjienspil, word in Figuur 1 voorgestel.

In-prosesmeting berus op 'n skakeling, d.m.v. 'n sensor, tussen die werkstuk en die RNB-masjien [1]. Die sensor funksioneer tydens meting volgens 'n elektroniese skakelaarbeginsel. Gedurende die meetproses word die masjienspil met die sensor na die verlangde meetposisie gedryf, sodat die meetkop nou met. 'n bepalde (meet) spoed teen die meetvlak druk. Tydens kontak word ' $n$ snellersein aan die beheereenheid van die RNB-masjien gestuur om die huidige kobrdinate van die kontakpunt as die verlangde lesing te stoor. Vir 'n buite-toleransie kondisie kan korrektiewe aksie nou geneem word deur die gereedskap-afwykings in die masjineringsprogram aan te pas. Die meetprogram vorm dus 'n subprogram van die masjineringsprogram. Sodoende vorm IPM nou 'n geintegreerde deel van die vervaardigingsproses.

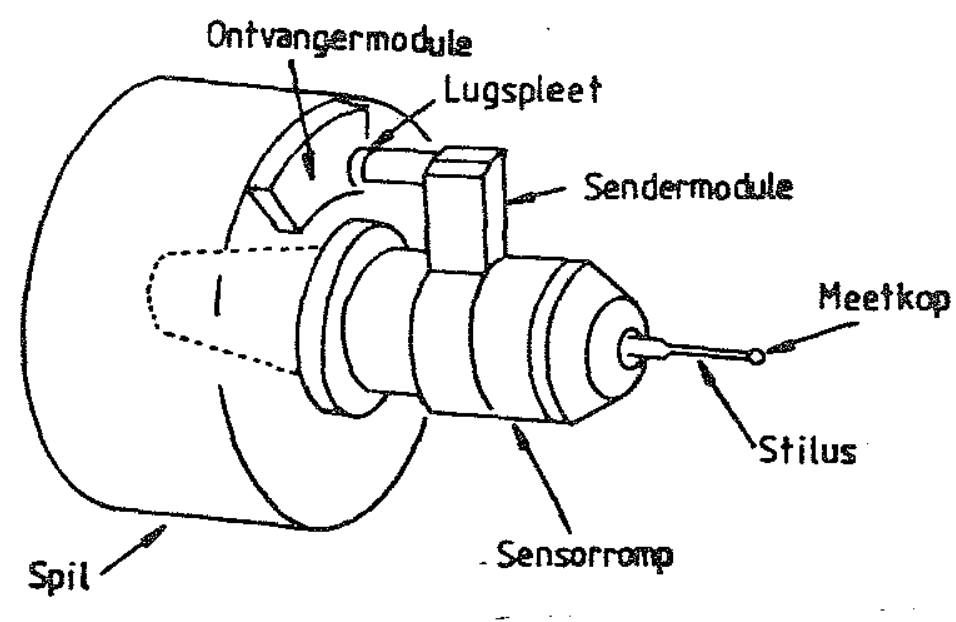

Figur 1 Die sensor gelaai in die masjienspil 
Die sensor bestaan hoofsaaklik uit ' $n$ sensorromp, sendermodule, stilus en die meetkop. 'n Ontvangermodule word op die masjienspil gemonteer. Die stilus beskik oor 'n verbybeweging ("overtrave1") eienskap, wat alom-direksioneel kan deflekteer, en wat na kontak (meting) weer na die oorspronklike posisie kan terugkeer. 'n Interne meganieseeenheid, wat oor 'n kenmerkende uittree-impedansie beskik, is aan die stilus gemonteer. Sodra die stilus deflekteer, verander dié uittree-impedansie on die snellersein voort te bring. Elektriese energie aan, en seine vanaf die sensor word m.b.v. 'n induktiewe transmissiestelsel bewerkstellig. Dié stelsel is ook met die RNB-masjien se gereedskapruilingstelsel versoenbaar om gereedskapruiling van gereedskapstukke én die sensor tydens die masjineringsproses moontlik te mak.

Tegnieke:-

IPM omskryf die verskillende meettegnieke wat deur die IPMS uitgevoer kan word, n1.:

- opstelling van setmate en werkstukke

- prosesbeheer tydens vervardiging

- inspeksie van die werkstuk of finale komponent

Meetresultate kan ook vir dokumentasie doeleindes uitgedruk word deur ' $n$ drukker an die RNB-masjien te koppel.

Verskillende meetmetodes met die IPMS word in Figuur 2 angedui.

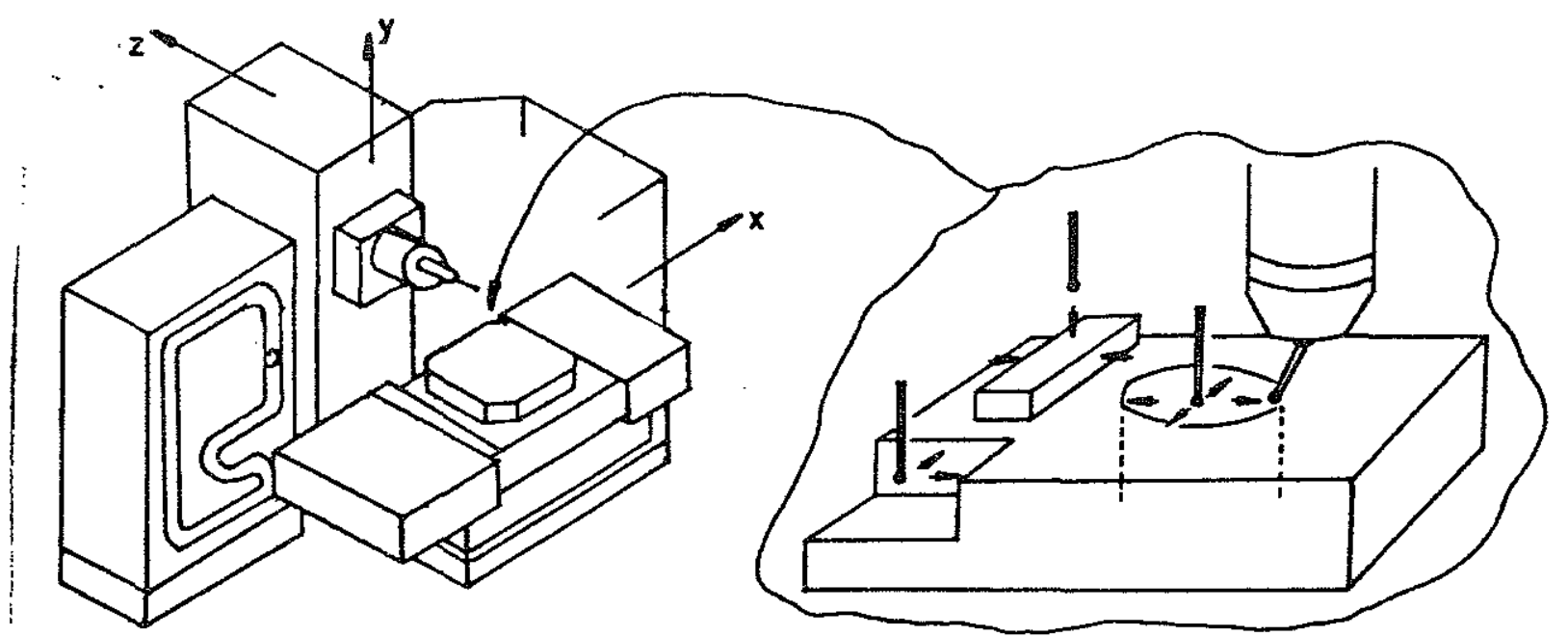

Figuur 2 Meetmetodes met die IPMS 
Toepassingsareas en koste:-

Die hoof toepassingsareas van IPM is by die vervaardiging van klein tot medium lotgroottes deur RNB-draaibanke en -masjiensentrums. Die gebruik van IPM by massaproduksie deur RNB-masjiene kan tot nie-optimale masjienbenutting 1ei. Daarom sal na-proses meetstasies byvoorbeeld, meer angewese wees vir massaproduksie. Die koste verbonde aan die installering van die IPMT beloop ongeveer $5 \%$ tot $10 \%$ van die totale anvanklike koste van die masjienwerktuig.

VoordeIe:-

IPM kan verskeie voordele inhou t.o.v. produktiwiteit en outomatisasie [2]. Die vernaamste hiervan is:

-Onmiddelike terugvoering van meetresultate om korrektiewe aksie vir verdere masjinering van die werkstuk te verseker. -Vermindering van o.a. : opsteltyd, arbeid, leityd en herwerk. -Geen materiaalhantering is ter sprake nie, soos wel die geval is indien die werkstuk in die inspeksiekamer, of by meetstasies gemeet word.

-Verbetering in akkuratheid deurdat die werkstuk nie verwyder en geherposisioneer moet word in die setmat nie. Verder word meet-en berekeningsfoute, wat nou hoofsaaklik bepaal word deur die ontwikkeling van die meetprogram, geminimeer.

Gedurende ' $n$ toetsfase is die opsteltyd van 'n spesifieke setmat m.b.v. in-prosesmeting vergelyk met konvensionele opstelling. Die konvensionele opstelmetode het die gebruik van o.a. klokwysers en lengtestawe behels. 'n Tydbesparing van tot $78 \%$ is verkry met die gebruik van IPM. Deur slegs 'n enkele sleutel op die beheerpaneel van die RNB-masjien te druk, kon die setmat se bepalde verwysingspunt telkens (outomaties) geverifieer word. 


\section{KALIBRASIE YAN IN-PROSESMETING}

Vir die effektiewe funksionering van die in-proses meetstelsel is dit noodsaaklik dat die meetstelsel gekalibreer word [3]. Gedurende die kalibrasieproses word die IPMT se meganiese en elektroniese karakteristieke asook ander dinamiese faktore met die RNB-masjien gesinchroniseer. Omrede die stilus tydens kontak deflekteer, is die meetkop nie noodwendig in lyn met die spilsenterlyn nie. Daarom is dit belangrik om die meetkopposisie relatief tot die masjienverwysing vas te stel, voordat die IPMS vir meting gebruik word. Verder is daar ook 'n tydsvertraging teenwoordig vandat die meetkop met 'n meetvlak kontak gemaak het totdat die masjienbeheereenheid die snellersein registreer. Daar moet dus ook vir dié tydsvertraging gekompenseer word.

Die kalibrasieproses word teen 'n standaardring, wat vooraf konvensioneel opgestel is, deurgevoer. Die kalibrasieprosedure bestaan basies uit drie stappe:

1) Bepaling van die kobrdinate (posisie) van die meetkop relatief tot die spilsenterlyn: die meetstelsel voer 'n sentreringsproses (4-punt meting) uit om die gemete middelpunt van die standaardring te vergelyk met die werklike middelpunt. Die afwykings $\Delta \mathrm{X}$ en $\Delta \mathrm{Y}$ word dan hiervolgens bereken.

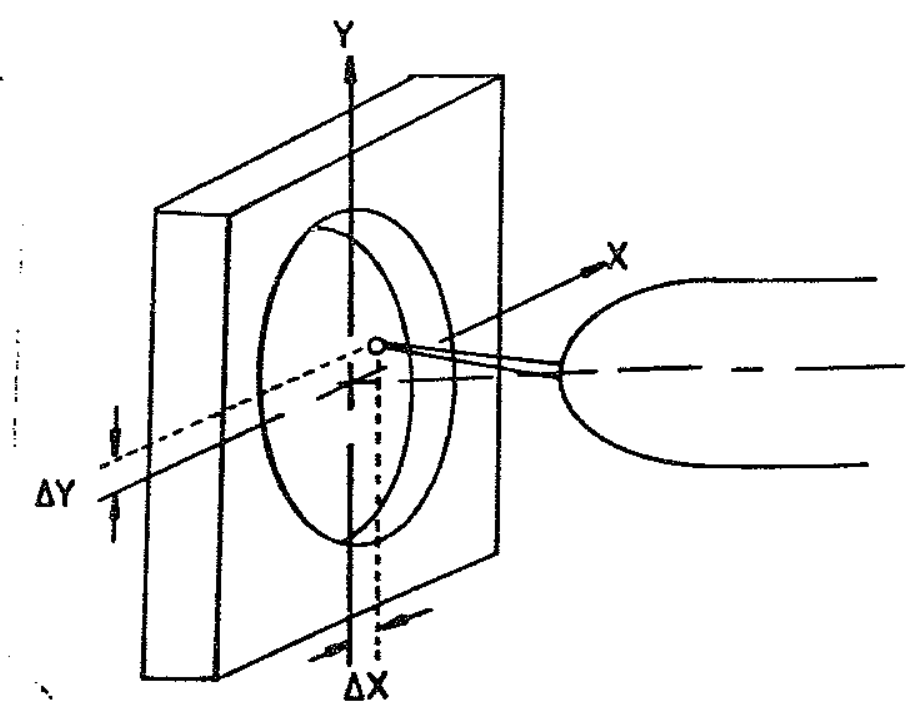

Figuur 3 Bepaling van die meetkop-afwykings 
2) Die sensorlengte (Z-kobrdinat) word bepal teen die bo-punt van die standaardring, wat as die verwysingsvlak in die Z-rigting beskou word. Die gemete warde word dan vergelyk met die werklike afstand om die $\Delta$ Z-afwyking te verkry.

3) Die snellersein-tydsvertragingfaktore word bepaal in die spesifieke rigting warteen gemeet gaan word. In dié geval is die proses ' $n$ dimensionele meting wartydens die gemete diameter met die standaardiameter vergelyk word. Die verskil is die tydsvertragingfaktor (vir 'n spesifieke meetrigting), wat ook o.a. die diameter van die meetkop en ander dinamiese faktore insluit.

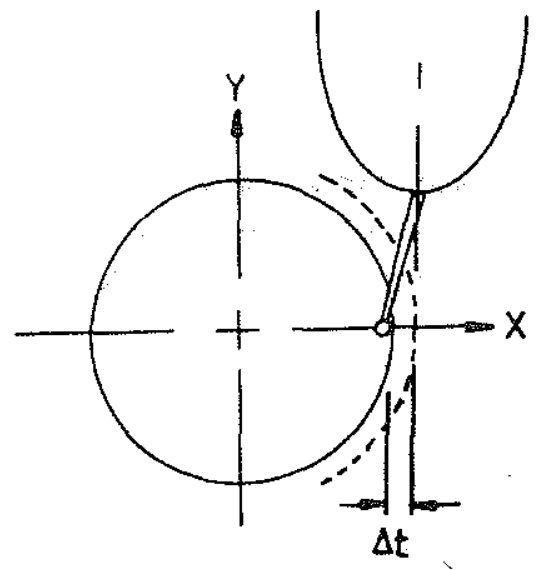

Figuur 4 Bepaling van die tydsvertragingfaktore

Die bepalde kompensasiefaktore word in spesifieke registers van die RNB-masjien gestoor, om nou vir kompensasie doeleindes gedurende die gebruik van die sensor te dien.

Die kalibrasieproses word outomaties deur 'n kalibrasieprogram (programmatuur) teen die gekalibreerde standaardring wat in die werksarea van die RNB-masjien geposisioneer word, deurgevoer. Vanwell die termiese verplasing van die masjienstruktuur en ander dinamiese faktore, moet die kalibrasieprosedure met gereelde tydsintervalle herhal word.

Twee belangrike aspekte omtrent die kalibrasie van die IPMS is die meetvoerspoed en meetrigting. Hoe stadiger die meetvoerspoed, hoe beter is die akkuratheid en herhaalbaarheid van die meetproses, maar hoe langer duur die kalibrasieproses. Met 'n 
meetvoerspoed van $10 \mathrm{~mm} / \mathrm{min}$ is ' $\mathrm{n}$ akkuraatheid, met die meet van ' $n$ standaarddimensie, van $1 \mu \mathrm{m}$ verkry, maar die kalibrasieproses het ongeveer 45 minute geduur. In teensteliing hiermee, het die kalibrasieproses 10 minute geduur met ' $n$ meetvoerspoed van $50 \mathrm{~mm} / \mathrm{min}$ en 'n akkuraatheid van $6 \mu \mathrm{m}$ is toe verkry. ' $\mathrm{n}$ Stadige meetvoerspoed kan egter gebruik word war kritieke karakteristieke gemeet moet word. Dit is egter belangrik om teen dieselfde meetvoerspoed as warteen gemeet gaan word, te kalibreer. Indien dit nagelaat word, kan 'n onakkuraatheid van tot $50 \mu \mathrm{m}$ tydens dimensionele metings verkry word.

Vir die geldigheid van die kompensasiefaktore, is dit ook belangrik om in dieselfde rigting te kalibreer as warteen gemeet gaan word. Die rede hiervoor is dat die tydsvertragingfaktore direksioneel en nie alom-uniformig dieselfde is nie. Die mees algemene meetrigting en dus ook die kalibrasierigting, is in die reglynige $X-, Y-$, of $Z$-asbeweging van die masjienwerktuig.

\section{RWALIFIKASIE VAN IN-PROSESMETING}

Om in-prosesmeting effektief te implementeer, is dit uit 'n kwaliteits-oogpunt belangrik dat die in-proses meetstelsel (soos enige ander meetsisteem) met vasgestelde tydsintervalle gekwalifiseer word [4]. Sodoende kan die IPMS se vermok bepal word en gereeld geverifieer word teen spesifikasie of vooraf bepalde limiete. Die onakkuratheid van die IPMS kan ook gedurende IPM gebruik word vir kompensasie doeleindes, om sodoende die inherente onakkuratheid van die totale stelsel te minimeer.

Verskeie faktore kan bydra tot die effektiwiteit van IPM. Die faktor wat hoofsaaklik die vermol van die IPMS bepaal is die RNB-masjien self, t.o.v. presisie, geometrie en stabiliteit (veral onder varierende omgewingstoestande soos temperatuur). Dit is dus noodsaaklik om eers die vryspeling en steekfout te minimeer deur die RNB-masjien optimal in te stel (m.b.v. 'n Laser interferometer). 
Deur die IPMT (sensor) afsonderlik te kwalifiseer, is aanvanklik probleme ondervind, aangesien ' $n$ herhaalbaarheid van $0,5 \mu \mathrm{m}$ tot $2,0 \mu \mathrm{m}$ verwag is [3]. Volgens kwaliteitbeginsels sou dit beteken dat 'n meetinstrument met ' $n$ resolusie van ongeveer $0,1 \mu \mathrm{m}$ gebruik moes word. Die aspek en ander tegniese beperkings het daartoe gelei dat ' $n$ kwalifikasiemetode op die RNB-masjien self en m.b.v. 'n eksterne meetkoppelkas ontwikkel is. Op die wyse is daar toe ' $n$ aanduiding van die in-proses meettoerusting se vermol verkry $(1,3 \mu m)$.

Vir die kwalifikasie van in-prosesmeting is 'n toetsstuk (Figur 5) ontwikkel om sodoende die akkuraatheid en herhalbarheid van die IPMS op spesifieke posisies te bepaal. Lesings m.b.v. die sensor word geneem tussen die gekalibreerde meetpunte, vanaf ' $n$ verwysingsmeetpunt in die $X$ - en Y-rigting van die RNB-masjien. Lengte-yke word vir die kwalifikasie in die Z-rigting gebruik. Die toetsstuk word op verskillende posisies van die tafelblad geposisioneer, om sodoende ongeveer $95 \%$ van die RNB-masjien se werksvolume te betrek.

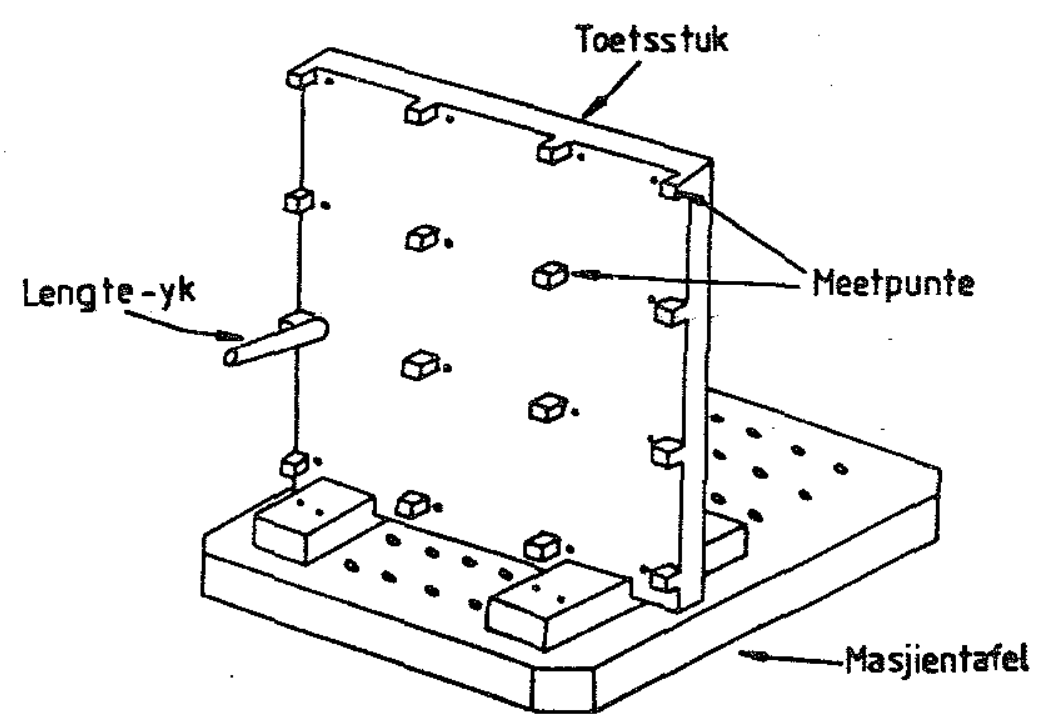

Figuur 5 Kwalifikasie-opstelling vir die IPMS

Op grond van toetse en eksperimente word 'n akkuraatheid en herhalbaarheid van ongeveer $8 \mu \mathrm{m}$ (onder bepaalde toestande) vir die IPMS voorsien. Indien die bydrae van die IPMT se vermok tot die totale stelsel bekend is, kan die voorafgaande kwalifikasieprosedure ook gebruik word om ' $n$ aanduiding van die RNB-masjien se vermol te verkry. 


\section{GEVOLGTREXKING}

Ter opsoming is dit belangrik on die volgende aspekte omtrent in-prosesmeting in gedagte te hou:

-Met in-prosesmeting word daar tot 'n groot mate voordeel getrek uit die RNB-masjien se presisie en beheervermok.

-Die in-proses meettoerusting (sensor) is geensins beter as die (RNB)-masjien warop dit gebruik word nie.

-In-prosesmeting moet nie beskou word as 'n vervanging van die inspeksie-departement nie, mar eerder as ' $n$ buigbare en akkurate alternatief tot die konvensionele benadering van meting tydens vervaardiging.

-Die kalibrasie en kwalifikasie aspekte is van groot belang, ten einde in-prosesmeting koste-effektief te implementeer.

Ofskoon in-prosesmeting 'n nuwe meettegnologie openbaar met wye navorsingsvelde en die probleem van kennis, ondervinding en standardisasie, behoort in-prosesmeting in Suid-Afrika meer bekend gestel te word, veral uit 'n produktiwiteits-oogpunt gesien. In-prosesmeting is een van die mees belowende tegnologiese ontwikkelings en die vooruitgang hiervan groei vinnig. Daarom behoort dié metode van meting tydens produksie, in die toekoms universeel aanvaar te word.

\section{VERWYSINGS}

[1] Barringer, P., 1985, "Probes Are Key To Control", American Machinist, p.69-71.

[2] "Touch Trigger Probes Increase Productivity", 1986, Precision Toolmaker, p.18-19.

[3] "Operation Manua1 For Automatic Measuring".

(4] "Quality $I^{n}$ (Saamgestel deur LIW, Opleiding en. Ontwikkeling), 1986. 